\title{
Influence of the First-wave COVID-19 Pandemic on Emergency Acute Coronary Syndrome: a Multicenter Retrospective Study From a Non-epicenter Region
}

\section{Qi Mao}

Xinqiao Hospital https://orcid.org/0000-0002-6040-0116

Jian-Hua Zhao

Xinqiao Hospital

Jian-Fei Chen

People's Hospital of Banan District

Qiang Xu

the Fifth People's Hospital of Chongqing

Zhong-Lin Xu

the Nineth People's Hospital of Chongqing

\section{Yang Yu}

People's Hospital of Dianjiang District

\section{Ying Zhang}

Emergency Medical Center of Chongqing

\section{Qiang Li}

People's Hospital of Nanchuan District

\section{Xiao-Hua Pang}

the Three Gorges Central Hospital

\section{Zheng-Gong Li}

Zhongshan Hospital of Chongqing

\section{Bo-Li Ran}

Third Hospital of Chongqing

\section{Zhi-Hui Zhang}

Southwest Hospital

\section{Zhi-Feng Li}

Yongchuan Hospital of Chongqing Medical University

\section{Chun-Yu Zeng}

Daping Hospital

\section{Shi-Fei Tong}

the Third Affiliated Hospital of Chongqing Medical University

Jun Jin 
Xinqiao Hospital

Lan Huang

Xinqiao Hospital

Xiao-Hui Zhao ( $\sim$ doctorzhaoxiaohui@yahoo.com )

Xinqiao Hospital

\section{Research}

Keywords: COVID-19, Acute coronary syndrome, Invasive therapy, Emergency care, Non-epicenter region

Posted Date: November 10th, 2021

DOI: https://doi.org/10.21203/rs.3.rs-1010545/v1

License: (c) (1) This work is licensed under a Creative Commons Attribution 4.0 International License. Read Full License 


\section{Abstract}

Background: The COVID-19 pandemic presented severe challenges to emergency practice of acute coronary syndrome (ACS). However, poor evidence was shown on ACS in a non-hot-spot region. We sought to clarify the influence of the first-wave COVID-19 pandemic on emergency ACS from a nonepicenter region.

Methods: This retrospective multicenter study was conducted in emergency ACS patients during the pandemic (from 2020-01-23 to 2020-03-29) and the ones during the same period in 2019. Clinical characteristics, timeline parameters and treatment strategies were compared between different groups. Association of the pandemic with non-invasive therapy was further assessed.

Results: Compared with 2019, ACS had a drop in admission (267 cases vs. 475 cases) and invasive therapy (140 cases vs. 318 cases). Also, process delays were detected including the period from symptom onset to first medical contact (S-to-FMC, $5 \mathrm{~h}$ vs. 2.5h), the period from FMC to electrocardiogram (ECG) completed (8min vs. $4 \mathrm{~min}$ ) and the period from FMC to dual antiplatelet therapy (FMC-to-DAPT, $25 \mathrm{~min}$ vs. $19 \mathrm{~min}$ ). Primary percutaneous coronary intervention (PPCl) decreased by $54.9 \%$ in STEMI and early invasive therapy decreased by $59.2 \%$ in NSTE-ACS. The proportion of invasive therapy in NSTE-ACS decreased more than in STEMI (16.9\% vs. $10.1 \%)$ with longer process delay. The pandemic was associated with increased non-PPCl in STEMI $(\mathrm{OR}=1.707,95 \% \mathrm{Cl} 1.082-2.692, \mathrm{P}=0.021)$ and elevated medication in NSTE-ACS $(\mathrm{OR}=2.029,95 \% \mathrm{Cl} 1.268-3.247, \mathrm{P}=0.003)$, respectively.

Conclusion: Even in a non-epicenter region, the first-wave COVID-19 pandemic caused a significant reduction of invasive therapy and evident process delays in emergency ACS.

\section{Introduction}

Acute coronary syndrome (ACS) is one of the most common chest pain emergencies, including STsegment-elevation myocardial infarction (STEMI) and non-ST-segment elevation acute coronary syndrome (NSTE-ACS) [1]. Prognosis of ACS is highly dependent on standard procedures for chest pain emergency including early transfer, prompt diagnosis, risk stratification and timely intervention [2]. Since the outbreak in December 2019, coronavirus-2019 disease (COVID-19) caused by severe acute respiratory syndrome-coronavirus-2 (SARS-CoV-2) has rapidly spread to the worldwide and been a devastating viral pandemic $[3,4]$. As of August in 2021, a total of more than 210 million cases have been diagnosed and approximately 4.4 million confirmed deaths [5]. The COVID-19 pandemic posed severe burden and challenges to emergency network and rescue procedure.

Reasonable medical responses between COVID-19 prevention and revascularization are critical for rescuing emergency ACS [6]. After the first-wave outbreak, the findings from Europe revealed that hospital admissions for all types of ACS decreased by approximately $40 \%$, meanwhile numbers of PCI procedures had an estimated $30 \%-40 \%$ reduction [7, 8]. Similarly, the data from U.S. showed a $43.7 \%$ decline in hospitalizations during the first-phase pandemic [9]. Previous evidences about the impact of the 
pandemic on ACS were still mostly concentrated in high-intensity epicenters [10]. However, poor evidence on clinical characteristics and intervention strategy remained for ACS in non-hot-spot regions; and fewer studies focused on the effect of the pandemic on non-invasive therapy in STEMI and NSTE-ACS, respectively. Moreover, it is also not clear that real profile of ACS emergency during the first-wave epidemic in the absence of mature experience.

\section{Methods}

\section{Study population}

This was a retrospective multicenter study with a total of 14 hospitals involved. The first-wave COVID-19 pandemic was defined as the period from January 23 to March 29 in 2020. On January 23 of Wuhan's lockdown, our city also raised local health response to curb the spread of the epidemic. During the pandemic, a total of 576 infection cases occurred in this region including 570 cured and 6 deaths; then public health response was downgraded on March 29 owing to complete clearance of infection cases (Figure 1). In our study, emergency ACS patients during the same period in 2019 were also included to reduce the confounding effect of seasonal alternation and holiday events. In addition, the patients with confirmed or suspected COVID-19 were excluded. Our study protocol complied with the Declaration of Helsinki and was approved by Xinqiao Hospital Ethics Committee, Army Medical University.

\section{Emergency procedure during the pandemic}

All emergency patients were screened for SARS-COV-2 according to Clinical Guideline of Diagnosis and Treatment (7th edition) [11]. Based on fever symptoms and epidemiological history, admitted patients were first assigned to emergency or fever clinics. With the assistance of COVID-19 expert team in hospital, the patients with confirmed or suspected COVID-19 would be transferred to the designated hospitals quickly. The patients without exclusion of COVID-19 temporarily would be transferred to special wards for isolation, and if further test was positive, they would be transferred to the designated hospitals as soon as possible. Whether to perform invasive therapy mainly depended on ischemic risk assessment and guideline recommendation $[12,13]$. The flowchart of chest pain procedure was shown in Figure 2.

\section{Data collection and definition}

Clinical data were obtained from medical records by trained clinicians in each hospital and were verified by another two investigators. Clinical characteristics included demographic data, admission signs, arrival periods, transferred methods, chest pain timelines and treatment strategy. Diagnostic criteria of ACS refer to the definitions of European Society of Cardiology guidelines for NSTE-ACS and STEMI [14, 15].Global Registry of Acute Coronary Events (GRACE) risk score is applied for prediction of risk in ACS and is calculated based on the clinical characteristics, electrocardiogram (ECG) performance and laboratory parameters at admission [16]. Transferred methods consisted of walk-in, in-hospital onset, emergency medical services and inter-facility transports; walk-in and in-hospital onset were deemed as nontransferred, while EMS and inter-facility transports were regarded as transferred. Chest pain timelines included the period from symptom onset to first medical contact (S-to-FMC), the period from FMC to 
electrocardiogram completed (FMC to ECG completed), the period from door to troponin completed and the period from FMC to dual antiplatelet therapy (FMC to DAPT) [17]. The duration of early invasive therapy is within 24 hours.

\section{Statistical analysis}

Continuous variables are presented as mean \pm SD for symmetric distributions and median (interquartile range, IQR) for skewed distributions. Categorical variables are expressed as frequency (percentage). For comparisons between groups, the $t$ test was performed for symmetric distributed variables, and nonparametric Mann-Whitney U test was applied for skewed distributed variables. Differences in categorical variables were assessed by the Chi-squared test or Fisher exact test. Taking non-invasive therapy as the dependent variable, we conducted logistic regression analysis to evaluate the association of COVID-19 pandemic with non-invasive therapy, and then sub-group analysis was utilized to further examine this correlation. Two-tailed $P$ values $<0.05$ were considered statistically significant. All statistical analyses were performed using SPSS software version 24.0 (SPSS, Inc, Chicago, Illinois).

\section{Results}

\section{Clinical characteristics and therapy strategies in emergency ACS}

A total of 742 emergency ACS patients with non-COVID-19 were enrolled in this study with 267 cases during the pandemic and 475 cases during the same period in 2019 (Table 1). Compared with 2019, ACS had a reduction in cases by $43.8 \%$ totally, while the cases of emergency STEMI and NSTE-ACS decreased by $47.8 \%$ and $38.1 \%$, respectively. Moreover, there were no differences in admission signs, GRACE scores, arrival period and transferred method ( $P>0.05$ ). Significant delays appeared in S-to-FMC (5.0h vs. 2.5h), FMC to ECG completed ( $8 \mathrm{~min}$ vs. $4 \mathrm{~min}$ ), door to troponin completed (13 $\mathrm{min}$ vs. $12 \mathrm{~min}$ ) and FMC to DAPT (25min vs. 19min) $(P<0.05)$ (Table 1$)$. 
Table 1

Clinical characteristic in emergency ACS before and during the pandemic

$\begin{array}{lll}\text { From 2019-01-23 to 2019- } & \begin{array}{l}\text { From 2020-01-23 to 2020- } \\ \text { 03-29 }\end{array} & \begin{array}{l}\mathrm{P} \\ \text { value }\end{array}\end{array}$

\section{Characteristics}

Age (years)

Male, n (\%)

Heart rate $(/ \mathrm{min})$

$\mathrm{SBP}(\mathrm{mmHg})$

DBP $(\mathrm{mmHg})$

Killip class

Killip class I, n (\%)

Killip class II, n (\%)

Killip class III, $\mathrm{n}(\%)$

Killip class IV, $\mathrm{n}(\%)$

Killip class $\geq I I, n(\%)$

$\operatorname{Scr}(\mu \mathrm{mol} / \mathrm{L})$

GRACE score in hospital

STEMI, n (\%)

Arrival during non-office hours, 211 (44.4)

$\mathrm{n}(\%)$

Non-transferred patients, n (\%)

S-to-FMC (hours)

FMC to ECG completed (min) $\quad 4(2-6)$

Door to Troponin completed

(min)

FMC to DAPT (min)

$19(17-22)$
$(\mathrm{N}=267)$

$67(56-76)$

0.175

$194(72.7)$

0.957

$78(68-90)$

$78(68-90)$

0.317

129 (115-148)

$132(112-150)$

0.351

78 (68-88)

80 (69-90)

0.207
311 (65.5)

106 (22.3)

$26(5.5)$

$25(5.3)$

159 (33.5)

74.0 (62.5-91.6)

140 (116-164)

278 (58.5)

259 (54.5)

$2.5(1.5-4.0)$

$12(11-14)$
177 (66.3)

55 (20.6)

10 (3.7)

$24(9.0)$

89 (33.3)

0.969

74.0 (62.0-95.0)

0.824

137 (116-162)

0.515

145 (54.3)

0.265

$115(43.1)$

0.722

164 (61.4)

0.069

$5.0(3.0-9.0)$

$<0.001$

$8(5-15)$

$<0.001$

$13(12-15)$

0.001

25 (21-32)

$<0.001$

Data are expressed as median (interquartile range, IQR) or number (percentage) as appropriate. ACS. acute coronary syndrome;

SBP: systolic blood pressure; DBP. diastolic blood pressure; SCr. serum creatinine; STEMI: ST-segmentelevation myocardial infarction; $S$-to-FMC. the period from symptom onset to first medical contact; ECG: electrocardiogram; DAPT: dual antiplalet therapy. 
Primary percutaneous coronary intervention (PPCI) decreased by $54.9 \%$ in STEMI and early invasive therapy decreased by $59.2 \%$ in NSTE-ACS after the outbreak. Further analysis revealed that delays of timeline parameters occurred in both STEMI and NSTE-ACS during the pandemic $(P<0.05)$. As compared to 2019 , the proportion of PPCl significantly declined in STEMI $(69.0 \%$ vs. $79.1 \%, P<0.05)$; similar but more serious trend also appeared in early invasive therapy for NSTE-ACS $(32.8 \%$ vs. $49.7 \%, P<0.05)$ (Table 2). 
Table 2

Comparison of clinical characteristic for different emergency ACS types before and during the pandemic

STEMI

From 2019- $\quad$ From 2020-

$01-23$ to

2019-03-29

$01-23$ to

2020-03-29

Characteristics

$(\mathrm{N}=278)$

64 (55-74)

$(\mathrm{N}=145)$

Age (years)

Male, n (\%)

Heart rate

(/min)

$\mathrm{SBP}(\mathrm{mmHg})$

$\operatorname{DBP}(\mathrm{mmHg})$

Killip class

Killip class I, n $174(62.6)$

(\%)

Killip class II, $\mathrm{n} \quad 66(23.7)$

(\%)

Killip class III, n $14(5.0)$

(\%)

Killip class IV, $\mathrm{n}$

(\%)

Killip class $\geq I I, n \quad 104(37.4)$

$(\%)$

$\operatorname{Scr}(\mu \mathrm{mol} / \mathrm{L})$

$74.0(63.0-$

$91.8)$

GRACE score in

hospital

Arrival during

non-office

hours, n (\%)

Non-transferred $132(47.5)$

patients, $\mathrm{n}(\%)$

$77(65-90)$

$126(109-$

150)

$79(66-92)$

$21(14.5)$

$55(37.9)$

$73.0(61.5-$

92.5)

$143(120$

169)

$67(46.2)$

$127(45.7)$

$81(55.9)$
NSTE-ACS

P From 2019- From 2020- $P$ value $\quad 01-23$ to $01-23$ to value 2019-03-29 2020-03-29

$(\mathrm{N}=197)$

$(\mathrm{N}=122)$

$0.442 \quad 67(58-76) \quad 68(60-77) \quad 0.338$

$0.317 \quad 127(64.5) \quad 86(70.5)$

0.267

$0.178 \quad 78(67-90) \quad 78(69-90)$

0.909

0.685

$133(120-$

$135(122-$

151)

0.661

152)

$0.584 \quad 80(69-88) \quad 80(70-89)$

0.211

0.584

$137(69.5)$

$86(70.5)$

$40(20.3) \quad 24(19.7)$

$12(6.1)$

7 (5.7)

$2(1.0)$

$3(2.5)$

$0.916 \quad 55(27.9)$

$34(27.9)$

0.992

0.779

74.8 (62.0-

91.0)

$75.0(62.0-$

101.0)

0.497

0.961

134 (107-

163)

129 (110-

153)

$0.918 \quad 84(42.6)$

48 (39.3)

0.561

$0.102 \quad 127(64.5)$

$83(68.0)$

0.514

Data are expressed as median (interquartile range, IQR) or number (percentage) as appropriate. NSTEACS. non-ST-segment elevation acute coronary syndrome; PPCl: primary percutaneous coronary intervention. 


\begin{tabular}{|c|c|c|c|c|c|c|}
\hline & STEMI & & & NSTE-ACS & & \\
\hline $\begin{array}{l}\text { S-to-FMC } \\
\text { (hours) }\end{array}$ & $2.5(1.5-4.0)$ & $4.5(3.0-9.0)$ & $<0.001$ & $\begin{array}{l}2.5(1.7- \\
4.0)\end{array}$ & $\begin{array}{l}6.0(3.0- \\
10.0)\end{array}$ & $<0.001$ \\
\hline $\begin{array}{l}\text { FMC to ECG } \\
\text { completed (min) }\end{array}$ & $4(2-6)$ & $6(4-13)$ & $<0.001$ & $4(3-6)$ & $10(7-15)$ & $<0.001$ \\
\hline $\begin{array}{l}\text { Door to } \\
\text { Troponin } \\
\text { completed (min) }\end{array}$ & $12(11-15)$ & $13(12-15)$ & 0.023 & $13(11-14)$ & $13(12-15)$ & 0.013 \\
\hline $\begin{array}{l}\text { FMC to DAPT } \\
\text { (min) }\end{array}$ & $19(17-22)$ & $24(20-32)$ & $<0.001$ & $19(17-22)$ & $26(22-33)$ & $<0.001$ \\
\hline PPCl, n (\%) & $220(79.1)$ & $100(69.0)$ & 0.021 & - & - & - \\
\hline $\begin{array}{l}\text { Thrombolysis, n } \\
\text { (\%) }\end{array}$ & $11(4.0)$ & $10(6.9)$ & 0.186 & - & - & - \\
\hline $\begin{array}{l}\text { Early invasive } \\
\text { strategy, n (\%) }\end{array}$ & - & - & - & $98(49.7)$ & $40(32.8)$ & 0.003 \\
\hline $\begin{array}{l}\text { Data are expresse } \\
\text { ACS. non-ST-segn } \\
\text { intervention. }\end{array}$ & $\begin{array}{l}\text { s median (in } \\
\text { t elevation a }\end{array}$ & $\begin{array}{l}\text { uartile rang } \\
\text { coronary sy }\end{array}$ & $\begin{array}{l}\text { or nu } \\
\text { me; } P f\end{array}$ & $\begin{array}{l}\text { er (percen } \\
\text { primary } p \epsilon\end{array}$ & $\begin{array}{l}\text { as approp } \\
\text { aneous cor }\end{array}$ & NSTE- \\
\hline
\end{tabular}

\section{Comparisons between different groups in emergency ACS during the pandemic}

The results showed that NSTE-ACS group had older age (68 years vs. 65 years, $\mathrm{P}=0.046$ ) and higher systolic blood pressure $(135 \mathrm{mmHg}$ vs. $126 \mathrm{mmHg}, P=0.005)$ than STEMI group. STEMI group had higher GRACE scores (143 vs. $129, \mathrm{P}=0.005)$ and less non-transferred patients ( $55.9 \%$ vs. $68.0, \mathrm{P}=0.042)$ than NSTE-ACS during the pandemic. In timeline parameters, longer process delay occurred in the period from FMC to ECG completed (10min vs. $6 \mathrm{~min}, \mathrm{P}<0.001$ ) for NSTE-ACS (Table 3 ). 
Table 3

Comparison of clinical characteristic between different emergency ACS types during the pandemic

\begin{tabular}{|c|c|c|c|}
\hline & \multicolumn{3}{|c|}{ From $2020-01-23$ to $2020-03-29$} \\
\hline & STEMI & NSTE-ACS & $P$ value \\
\hline Characteristics & $(\mathrm{N}=145)$ & $(\mathrm{N}=122)$ & \\
\hline Age (years) & $65(56-76)$ & $68(60-77)$ & 0.046 \\
\hline Male, n (\%) & $108(74.5)$ & $86(70.5)$ & 0.466 \\
\hline Heart rate $(/ \mathrm{min})$ & $77(65-90)$ & $78(69-90)$ & 0.530 \\
\hline $\mathrm{SBP}(\mathrm{mmHg})$ & $126(109-150)$ & $135(122-151)$ & 0.005 \\
\hline $\mathrm{DBP}(\mathrm{mmHg})$ & $79(66-92)$ & $80(70-89)$ & 0.383 \\
\hline \multicolumn{4}{|l|}{ Killip class } \\
\hline Killip class I, n (\%) & $91(62.8)$ & $86(70.5)$ & \\
\hline Killip class II, n (\%) & $31(21.4)$ & $24(19.7)$ & \\
\hline Killip class III, n (\%) & $3(2.1)$ & $7(5.7)$ & \\
\hline Killip class IV, n (\%) & $21(14.5)$ & $3(2.5)$ & \\
\hline Killip class $\geq I I, n(\%)$ & $55(37.9)$ & $34(27.9)$ & 0.082 \\
\hline $\operatorname{Scr}(\mu \mathrm{mol} / \mathrm{L})$ & $73.0(61.5-92.5)$ & $75.0(62.0-101.0)$ & 0.607 \\
\hline GRACE score in hospital & $143(120-169)$ & $129(110-153)$ & 0.005 \\
\hline Arrival during non-office hours, $\mathrm{n}(\%)$ & $67(46.2)$ & $48(39.3)$ & 0.259 \\
\hline Non-transferred patients, n (\%) & $81(55.9)$ & $83(68.0)$ & 0.042 \\
\hline S-to-FMC (hours) & $4.5(3.0-9.0)$ & $6.0(3.0-10.0)$ & 0.193 \\
\hline FMC to ECG completed (min) & $6(4-13)$ & $10(7-15)$ & $<0.001$ \\
\hline Door to Troponin completed (min) & $13(12-15)$ & $13(12-15)$ & 0.516 \\
\hline FMC to DAPT (min) & $24(20-32)$ & $26(22-33)$ & 0.096 \\
\hline
\end{tabular}

Table 4 revealed that no differences appeared in admission signs between different therapy strategies for both STEMI and NSTE-ACS. In STEMI, PPCI group had more non-transferred patients (62.0\% vs. $42.2 \%$, $\mathrm{P}=0.026)$ and longer $\mathrm{S}$-to-FMC period (5.0h vs. $3.8 \mathrm{~h}, \mathrm{P}=0.031$ ) than non-PPCl group; yet longer delays occurred in FMC to ECG (23min vs. $5 \mathrm{~min}, \mathrm{P}<0.001)$, door to troponin (14min vs. $13 \mathrm{~min}, \mathrm{P}=0.019$ ) and 
FMC to DAPT (43min vs. $22 \mathrm{~min}, \mathrm{P}<0.001$ ) for non-PPCl group; and thrombolysis accounted for only $22.2 \%$ of non-PPCl. In NSTE-ACS, no differences existed in timeline parameters between early invasive strategy and medication $(P>0.05)$. 
Table 4

Comparison of clinical characteristic between different therapy strategies for emergency ACS during the pandemic

\begin{tabular}{|c|c|c|c|c|c|c|}
\hline & \multicolumn{3}{|c|}{$\begin{array}{l}\text { STEMI From } 2020-01-23 \text { to } 2020- \\
03-29\end{array}$} & \multicolumn{3}{|c|}{$\begin{array}{l}\text { NSTE-ACS From 2020-01-23 to 2020- } \\
03-29\end{array}$} \\
\hline & PPCl & Non-PPCl & $\begin{array}{l}P \\
\text { value }\end{array}$ & $\begin{array}{l}\text { Early } \\
\text { invasive } \\
\text { strategy }\end{array}$ & Medication & $\begin{array}{l}P \\
\text { value }\end{array}$ \\
\hline Characteristics & $(\mathrm{N}=100)$ & $(\mathrm{N}=45)$ & & $(\mathrm{N}=40)$ & $(\mathrm{N}=82)$ & \\
\hline Age (years) & $\begin{array}{l}64(55- \\
75)\end{array}$ & $70(57-78)$ & 0.091 & $67(58-75)$ & $69(62-77)$ & 0.270 \\
\hline Male, n (\%) & $77(77.0)$ & $31(68.9)$ & 0.300 & $32(80.0)$ & $54(65.9)$ & 0.108 \\
\hline Heart rate $(/ \mathrm{min})$ & $\begin{array}{l}75(64- \\
88)\end{array}$ & $81(66-95)$ & 0.159 & 78 (70-91) & $78(67-89)$ & 0.499 \\
\hline $\mathrm{SBP}(\mathrm{mmHg})$ & $\begin{array}{l}125(110- \\
150)\end{array}$ & $\begin{array}{l}132(109- \\
150)\end{array}$ & 0.614 & $\begin{array}{l}137(110- \\
154)\end{array}$ & $\begin{array}{l}135(124- \\
151)\end{array}$ & 0.713 \\
\hline $\mathrm{DBP}(\mathrm{mmHg})$ & $\begin{array}{l}78(68- \\
91)\end{array}$ & $80(66-95)$ & 0.884 & $81(72-90)$ & $80(70-89)$ & 0.645 \\
\hline \multicolumn{7}{|l|}{ Killip class } \\
\hline Killip class I, n (\%) & $62(62.0)$ & $29(64.4)$ & & $31(77.5)$ & $55(67.1)$ & \\
\hline Killip class II, n (\%) & $22(22.0)$ & $9(20.0)$ & & $8(20.0)$ & $16(19.5)$ & \\
\hline Killip class III, n (\%) & $2(2.0)$ & $1(2.2)$ & & $1(2.5)$ & $6(7.3)$ & \\
\hline Killip class IV, n (\%) & $15(15.0)$ & $6(13.3)$ & & 0 & $3(3.7)$ & \\
\hline Killip class $\geq$ Il, n (\%) & $39(39.0)$ & $16(35.6)$ & 0.693 & $9(22.5)$ & $25(30.5)$ & 0.356 \\
\hline $\operatorname{Scr}(\mu \mathrm{mol} / \mathrm{L})$ & $\begin{array}{l}71.2 \\
(60.2- \\
91.4)\end{array}$ & $\begin{array}{l}78.0(66.5- \\
106.7)\end{array}$ & 0.239 & $\begin{array}{l}71.0(62.0- \\
91.5)\end{array}$ & $\begin{array}{l}80.0(62.5- \\
101.2)\end{array}$ & 0.243 \\
\hline $\begin{array}{l}\text { GRACE score in } \\
\text { hospital }\end{array}$ & $\begin{array}{l}139(119- \\
166)\end{array}$ & $\begin{array}{l}150(120- \\
182)\end{array}$ & 0.157 & $\begin{array}{l}122(112- \\
153)\end{array}$ & $\begin{array}{l}130(108- \\
153)\end{array}$ & 0.672 \\
\hline $\begin{array}{l}\text { Arrival during non- } \\
\text { office hours, } \mathrm{n}(\%)\end{array}$ & $51(51.0)$ & $16(35.6)$ & 0.084 & $20(50.0)$ & $28(34.1)$ & 0.092 \\
\hline $\begin{array}{l}\text { Non-transferred } \\
\text { patients, n (\%) }\end{array}$ & $62(62.0)$ & $19(42.2)$ & 0.026 & $27(67.5)$ & $56(68.3)$ & 0.930 \\
\hline S-to-FMC (hours) & $\begin{array}{l}5.0(3.0- \\
9.7)\end{array}$ & $\begin{array}{l}3.8(2.3- \\
6.0)\end{array}$ & 0.031 & $4.5(2.5-11.0)$ & $\begin{array}{l}6.0(3.6- \\
10.0)\end{array}$ & 0.520 \\
\hline
\end{tabular}

Data are expressed as median (interquartile range, IQR) or number (percentage) as appropriate. 


\begin{tabular}{|c|c|c|c|c|c|c|}
\hline \multirow[b]{2}{*}{$\begin{array}{l}\text { FMC to ECG completed } \\
\text { (min) }\end{array}$} & \multicolumn{3}{|c|}{$\begin{array}{l}\text { STEMI From } 2020-01-23 \text { to } 2020- \\
03-29\end{array}$} & \multicolumn{3}{|c|}{$\begin{array}{l}\text { NSTE-ACS From 2020-01-23 to 2020- } \\
03-29\end{array}$} \\
\hline & $5(3-7)$ & $23(10-49)$ & $<0.001$ & $10(8-16)$ & $9(7-15)$ & 0.523 \\
\hline $\begin{array}{l}\text { Door to Troponin } \\
\text { completed (min) }\end{array}$ & $\begin{array}{l}13(12- \\
14)\end{array}$ & $14(12-19)$ & 0.019 & $14(11-15)$ & $13(12-14)$ & 0.630 \\
\hline FMC to DAPT (min) & $\begin{array}{l}22(19- \\
25)\end{array}$ & $43(31-87)$ & $<0.001$ & $26(23-32)$ & $25(22-33)$ & 0.479 \\
\hline Thrombolysis, n (\%) & 0 & $10(22.2)$ & $<0.001$ & - & - & - \\
\hline
\end{tabular}

\section{Association between the pandemic and non-invasive therapy in emergency ACS}

Logistic regression analysis was performed to explore the association of COVID-19 pandemic with noninvasive therapy in STEMI and NSTE-ACS. The results indicated the pandemic was associated with increased non-PPCI in STEMI $(\mathrm{OR}=1.707,95 \% \mathrm{Cl} 1.082-2.692, \mathrm{P}=0.021)$ and also correlated with elevated medication in NSTE-ACS significantly ( $\mathrm{OR}=2.029,95 \% \mathrm{Cl} 1.268-3.247, \mathrm{P}=0.003)$. Sub-group analysis further reconfirmed this correlation (Table 5). Furthermore, compositions of ACS and therapy strategy were shown in Figure 3. 
Table 5

Logistic analyses for the association of COVID-19 pandemic with non-invasive therapy in emergency ACS

Non-PPCI for STEMI

Cases OR $\quad 95 \% \mathrm{Cl}$

$423 \quad 1.707 \quad$ (1.082-

$2.692)$

Age

$\geq 60$

$<60$

265

158

$158 \quad 1.462$

(1.062-

$(0.640-$
$3.339)$

Gender

Male

Female

327

1.697

(0.9932.899)

$96 \quad 1.636$

(0.680-

3.936)

Killip class

I

IIV

159

264

1.822

(1.026-

3.237)

1.529

(0.723-

3.232)

GRACE score

$\geq 140$

$228 \quad 2.205$

(1.218-

3.991)

$<140$

195

1.153

(0.553-

2.404)

$0.053 \quad 213$

2.140

(1.222-

3.747)

$0.272 \quad 106$

2.198

(0.875-

$5.522)$
P

value

0.003

3.247)
(1.450-

4.266)

0.896

0.001
$1.067 \quad(0.404-$
$2.819)$

0.008

0.094

Office hours or

not

$\begin{array}{lllllllll}\text { Yes } & 229 & 2.387 & \begin{array}{c}(1.299- \\ 4.388)\end{array} & 0.005 & 187 & 2.302 & (1.223- & 0.010 \\ & & & & & & 4.332) & \\ \text { No } & 194 & 1.109 & \begin{array}{l}(0.550- \\ 2.236)\end{array} & 0.772 & 132 & 1.695 & \begin{array}{l}(0.828- \\ 3.471)\end{array} & 0.149 \\ & & & & & & \end{array}$

Transferred or

not 


\begin{tabular}{|lcccccccc|}
\hline \multicolumn{4}{|c}{ Non-PPCI for STEMI } & \multicolumn{5}{c|}{ Medication for NSTE-ACS } \\
\hline Yes & 210 & 2.170 & $\begin{array}{l}(1.159- \\
4.062)\end{array}$ & 0.015 & 109 & 3.185 & $(1.401-$ & 0.006 \\
\hline No & 213 & 1.452 & $\begin{array}{l}(0.734- \\
2.875)\end{array}$ & 0.284 & 210 & 1.584 & $(0.889-$ & 0.119 \\
\hline
\end{tabular}

\section{Discussion}

Our study found that ACS had significant delays in emergency procedure and an apparent drop in invasive therapy; the pandemic was associated with increased non-invasive therapy, especially for NSTEACS.

ACS often has acute chest pain as the onset symptom and further leads to heart failure, arrhythmia and even cardiac arrest [18]. Early identification and intervention for ACS contributes to improve cardiovascular outcomes, thus chest pain emergency is established to cope with these conditions [19]. Under a unified procedure, ACS patients are diagnosed, transferred and treated through chest pain emergency to reduce ischemic risk [20]. In STEMI, PPCI is generally recommended as priority while sometimes thrombolysis could be also considered as supplement to ensure timely reperfusion [21]. In NSTE-ACS, therapy strategy is mainly based on evaluation of ischemic risk; high-risk patients including hemodynamic instability, recurrent or refractory chest pain, malignant arrhythmia and severe heart failure should perform early invasive treatment within 24 hours or even 2 hours; medication could be considered to be optional for "relatively stable" patients [22]. COVID-19 not only directly increased cardiovascular risk through biological mechanisms, but also affected the prognosis of ACS patients by disrupting conventional treatment procedure [23]. Although previous studies provided some evidence of the pandemic's impact on ACS, this impact still remained unclear and unquantified in a non-epicenter.

Our findings firstly revealed decreased admissions and significant process delays after the first-wave epidemic. In hot-spot regions, similar results were also reported but larger reduction of hospitalization occurred in NSTE-ACS $[24,25]$. However, changes in ACS composition were not observed in our study maybe ascribed to relatively low-intensity epidemic and active admission. We proposed the main explanations for the decline in hospitalization. Firstly, the patients preferred to social distancing and medical avoidance owing to fear of infection. Secondly, strict social restrictions were not conducive for patients to obtain timely medical assistance at symptom onset. Thirdly, conventional treatment-oriented mode was transformed into epidemic control-oriented mode in medical institutions that meant more resources were spent on epidemic management thus the capacity for treatment might be weakened. Of note, although ACS had universal prolongations in emergency timelines, the delays in NSTE-ACS seemed more serious than in STEMI after the outbreak. Consistently, Metzler et al. showed a significant increase of ischemic time for ACS in Austria, yet lack of time-series analysis for emergency procedures [26]. Hamadeh et al. found the pandemic greatly affected STEMI presentation and care via process delay in a 
non-hot-spot region from America, but limited to small sample size and non-first-phase pandemic [27]. Arai et al. discovered that NSTEMI had longer time for transfer and examination than STEMI in Japan, whereas no considering season characteristics [28]. This effect should not be ignored considering that our data derived from a non-hot-spot region. Longer delay on NSTE-ACS might be mainly attributed to relatively lower ischemic risk and conservative response.

In terms of invasive therapy, Garcia et al. showed an estimated 38\% reduction in cardiac catheterization laboratory activations during the early phase of pandemic in U.S [29]. Kwok et al. revealed a decline in PPCl by $43 \%$ following the lockdown in England [30]. Xiang et al. reported an approximately $60 \%$ drop in epicenter (Hubei province) from China after the outbreak [31]. Likewise, our study found both PPCI for STEMI and early invasive treatment for NSTE-ACS dropped significantly. PPCI was still the preferred option for reperfusion in STEMI from our region rather than thrombolysis that also exhibited good adaptability of catheter-labs to the epidemic. Consistent with process delays, the proportion of invasive therapy in NSTE-ACS declined more than in STEMI suggesting conservative therapeutic behaviors. For STEMI, non-PPCI was more severely affected by the pandemic manifested as few thrombolysis and serious in-hospital delays that implied considerable non-PPCl patients rejected basic reperfusion therapy. This might be due to frequent informed risks and excessive protective measures in hospital, which further increased anxiety and insecurity of patients and reduced medical compliance. The absence of thrombolysis as supplement for PPCI would greatly increase the risk of life-threatening adverse events, thus it is essential for STEMI rescue to optimize in-hospital procedure [32]. Moreover, our study further indicated whether STEMI or NSTE-ACS, the pandemic increased the probability of non-invasive therapy in a non-epicenter. This surge in non-invasive strategy derived from both patient-level and hospital-level. On the one hand, patient's decision on treatment become more negative subjected to individual psychology affected by the pandemic; on the other hand, decision-making from hospital tended to be cautious in treatment based on prevention of nosocomial infections and lack of medical resources. As a non-hot-spot region under the first-wave epidemic, our findings might provide references for emergency ACS practice to other current non-epicenters.

Our study had several limitations. First, this study was subject to the biases inherent to its retrospective design. Second, clinical characteristics and timeline parameters were assessed by trained physicians in each center without central reconfirmation, potentially resulting biases and errors. Third, our study had a relatively small sample size and no longitudinal analysis. Fourth, the absence of PPCI parameters limited further analysis for mechanical reperfusion procedure. Last, it remained unclear how local policies of each hospital had altered due to the first-wave pandemic that might affect emergency procedure for chest pain.

\section{Conclusions}

Even in a non-epicenter region, a significant reduction occurred in invasive therapy with evident emergency process delays for ACS. In current epidemic, emergency procedure should be appropriately adjusted and considered for integration into chest pain practice. 


\section{Abbreviations}

COVID-19: Coronavirus-2019 disease; ACS: Acute coronary syndrome; STEMI: ST-segment-elevation myocardial infarction; NSTE-ACS: Non-ST-segment elevation acute coronary syndrome; PPCl: Primary percutaneous coronary intervention; SBP: Systolic blood pressure; DBP: Diastolic blood pressure; Scr: Serum creatinine; FMC: First medical contact; S-to-FMC: Symptom onset to FMC; DAPT: Dual antiplalet therapy; IQR: Interquartile range; OR: Odds ratio; Cl: Confidence interval.

\section{Declarations}

\section{Acknowledgments}

The authors express appreciation to all the participants and investigators for their support.

\section{Authors' contributions}

All authors have read the manuscript and agreed with the content. Zhao XH was responsible for the study concept and design. Data collection and cleaning were done by Zhao JH and Mao Q. Data analysis was performed by Mao Q. Mao Q wrote the draft of this manuscript that was revised and edited by Huang $L$ and Zhao XH. All authors contributed to the writing and revision of the paper.

\section{Funding}

This study was supported by grants from the National Natural Science Foundation of China (nos. 81670428).

\section{Availability of data and materials}

The data used or analyzed during this study are available from the corresponding author on reasonable request.

\section{Ethics approval and consent to participate}

The study was approved by Xinqiao Hospital Ethics Committee, Army Medical University (No.2021-07101). No additional ethical approval is needed.

\section{Consent for publication}

Not applicable.

\section{Competing interests}

The authors declare that they have no competing interests.

\section{References}


1. Libby P, Pasterkamp G, Crea F, Jang I. Reassessing the mechanisms of acute coronary syndromes. Circ Res. 2019; 124 (1): 150-160.

2. Danchin N, Popovic B, Puymirat E, Goldstein P, Belle L, Cayla G, et al. Five-year outcomes following timely primary percutaneous intervention, late primary percutaneous intervention, or a pharmacoinvasive strategy in ST-segment elevation myocardial infarction: the FAST-MI programme. Eur Heart J. 2020; 41 (7): 858-866.

3. Boukhris M, Hillani A, Moroni F, Annabi MS, Addad F, Ribeiro MH, et al. Cardiovascular implications of the COVID-19 pandemic: a global perspective. Can J Cardiol. 2020; 36 (7): 1068-1080.

4. Wiersinga WJ, Rhodes A, Cheng AC, Peacock SJ, Prescott HC. Pathophysiology, transmission, diagnosis, and treatment of coronavirus disease 2019 (COVID-19). JAMA. 2020; 324 (8): 782-793.

5. World Health Organization. Coronavirus disease-2019 situation report. Available online at: https://www.who.int/emergencies/diseases/novel-coronavirus-2019/situation-reports/ (accessed September 7, 2021)

6. Mahmud E, Dauerman HL, Welt FGP, Messenger JC, Rao SV, Grines C, et al. Management of acute myocardial infarction during the COVID-19 pandemic: A Position Statement From the Society for Cardiovascular Angiography and Interventions (SCAI), the American College of Cardiology (ACC), and the American College of Emergency Physicians (ACEP). J Am Coll Cardiol. 2020; 76 (11): 1375-1384.

7. Mafham MM, Spata E, Goldacre R, Gair D, Curnow P, Bray M, et al. COVID-19 pandemic and admission rates for and management of acute coronary syndromes in England. The Lancet. 2020; 396 (10248): 381-389.

8. De Filippo O, D'Ascenzo F, Angelini F, Bocchino PP, Conrotto F, Saglietto A, et al. Reduced rate of hospital admissions for ACS during covid-19 outbreak in Northern Italy. N Engl J Med. 2020; 383 (1): 88-89.

9. Bhatt AS, Moscone A, McElrath EE, Varshney AS, Claggett BL, Bhatt DL, et al. Fewer hospitalizations for acute cardiovascular conditions during the COVID-19 pandemic. J Am Coll Cardiol. 2020; 76 (3): 280-288.

10. Dehghani P, Davidson LJ, Grines CL, Nayak K, Saw J, Kaul P, et al. North American COVID-19 STsegment-elevation myocardial infarction (NACMI) registry: rationale, design, and implications. Am Heart J. 2020; 227: 11-18.

11. NHCotPsRo, China. Chinese clinical guideline for COVID-19 diagnosis and treatment (7th edition). National Health Committee, China. March 4, 2020. Available online at: http://www.nhc.gov.cn/yzygj/s7653p/202003/46c9294a7dfe4cef80dc7f5912eb1989.shtml (accessed March 4, 2020).

12. Xiang $D$, Huo $Y, G e J$. Expert consensus on operating procedures at chest pain centers in China during the coronavirus infectious disease-19 epidemic. Cardiol Plus. 2020; 5 (1): 21-32.

13. Han $Y$, Zeng $H$, Jiang $H$, Yang $Y$, Yuan Z, Cheng $X$, et al. CSC expert consensus on principles of clinical management of patients with severe emergent cardiovascular diseases during the COVID-19 epidemic. Circulation. 2020; 141 (20): e810-e816. 
14. Ibanez B, James S, Agewall S, Antunes MJ, Bucciarelli-Ducci C, Bueno H, et al. 2017 ESC guidelines for the management of acute myocardial infarction in patients presenting with ST-segment elevation. Eur Heart J. 2018; 39 (2): 119-177.

15. Rodriguez F, Mahaffey KW. Management of patients with NSTE-ACS: a comparison of the recent AHA/ACC and ESC guidelines. J Am Coll Cardiol. 2016; 68 (3): 313-321.

16. Fox KAA, Dabbous OH, Goldberg RJ, Pieper KS, Eagle KA, Van de Werf F, et al. Prediction of risk of death and myocardial infarction in the six months after presentation with acute coronary syndrome: prospective multinational observational study (GRACE). BMJ. 2006; 333 (7578): 1091.

17. Zhang Y, Yu B, Han Y, Wang J, Yang L, Wan Z, et al. Protocol of the China ST-segment elevation myocardial infarction (STEMI) Care Project (CSCAP): a 10-year project to improve quality of care by building up a regional STEMI care network. BMJ OPEN. 2019; 9 (7): e26362.

18. Crea F, Libby P. Acute Coronary Syndromes: The way forward from mechanisms to precision treatment. Circulation. 2017; 136 (12): 1155-1166.

19. Fan F, Li Y, Zhang Y, Li J, Liu J, Hao Y, et al. Chest pain center accreditation is associated with improved in-hospital outcomes of acute myocardial infarction patients in China: findings from the CCC-ACS project. J Am Heart Assoc. 2019; 8 (21): e013384.

20. Poldervaart JM, Langedijk M, Backus BE, Dekker IMC, Six AJ, Doevendans PA, et al. Comparison of the GRACE, HEART and TIMI score to predict major adverse cardiac events in chest pain patients at the emergency department. Int J Cardiol. 2017; 227: 656-661.

21. Omer MA, Tyler JM, Henry TD, Garberich R, Sharkey SW, Schmidt CW, et al. Clinical characteristics and outcomes of STEMI patients with cardiogenic shock and cardiac arrest. JACC: Cardiovasc Interv. 2020; 13 (10): 1211-1219.

22. Lemesle G, Laine M, Pankert M, Boueri Z, Motreff P, Paganelli F, et al. Optimal timing of intervention in NSTE-ACS without pre-treatment. JACC: Cardiovasc Interv. 2020; 13 (8): 907-917.

23. Adu-Amankwaah J, Mprah R, Adekunle AO, Ndzie NM, Adzika GK, Machuki JO, et al. The cardiovascular aspect of COVID-19. Ann Med. 2021; 53 (1): 227-236.

24. Secco GG, Zocchi C, Parisi R, Roveta A, Mirabella F, Vercellino M, et al. Decrease and delay in hospitalization for acute coronary syndromes during the 2020 SARS-CoV-2 pandemic. Can J Cardiol. 2020; 36 (7): 1152-1155.

25. Braiteh N, Rehman WU, Alom M, Skovira V, Breiteh N, Rehman I, et al. Decrease in acute coronary syndrome presentations during the COVID-19 pandemic in upstate New York. Am Heart J. 2020; 226 : 147-151.

26. Metzler B, Siostrzonek P, Binder RK, Bauer A, Reinstadler SJ. Decline of acute coronary syndrome admissions in Austria since the outbreak of COVID-19: the pandemic response causes cardiac collateral damage. Eur Heart J. 2020; 41 (19): 1852-1853.

27. Hammad TA, Parikh M, Tashtish N, Lowry CM, Gorbey D, Forouzandeh F, et al. Impact of COVID-19 pandemic on ST-elevation myocardial infarction in a non-COVID-19 epicenter. Catheter CardiovasC Interv. 2020; 97 (2): 208-214. 
28. Arai R, Fukamachi D, Ebuchi Y, Migita S, Morikawa T, Monden M, et al. Impact of the COVID-19 outbreak on hospitalizations and outcomes in patients with acute myocardial infarction in a Japanese Single Center. Heart Vessels. 2021; 36 (10): 1474-1483.

29. Garcia S, Albaghdadi MS, Meraj PM, Schmidt C, Garberich R, Jaffer FA, et al. Reduction in STsegment elevation cardiac catheterization laboratory activations in the United States during COVID19 pandemic. J Am Coll Cardiol. 2020; 75 (22): 2871-2872.

30. Kwok CS, Gale CP, Kinnaird T, Curzen N, Ludman P, Kontopantelis E, et al. Impact of COVID-19 on percutaneous coronary intervention for ST-elevation myocardial infarction. HEART. 2020; 106 (23): 1805-1811.

31. Xiang D, Xiang X, Zhang W, Yi S, Zhang J, Gu X, et al. Management and outcomes of patients with STEMI during the COVID-19 pandemic in China. J Am Coll Cardiol. 2020; 76 (11): 1318-1324.

32. Berwanger O, Lopes RD, Moia DDF, Fonseca FA, Jiang L, Goodman SG, et al. Ticagrelor versus clopidogrel in patients with STEMI treated with fbrinolysis. J Am Coll Cardiol. 2019; 73 (22): 28192828.

\section{Figures}




\section{COVID-19 outbreak Before 2020-01-23}

Regional public health eme rgency response From 2020-01-23 to 2020-03-29

\section{Regional public health eme rgency response downg raded after 2020-03-29}

Figure 1

COVID-19 outbreak and emergency response 


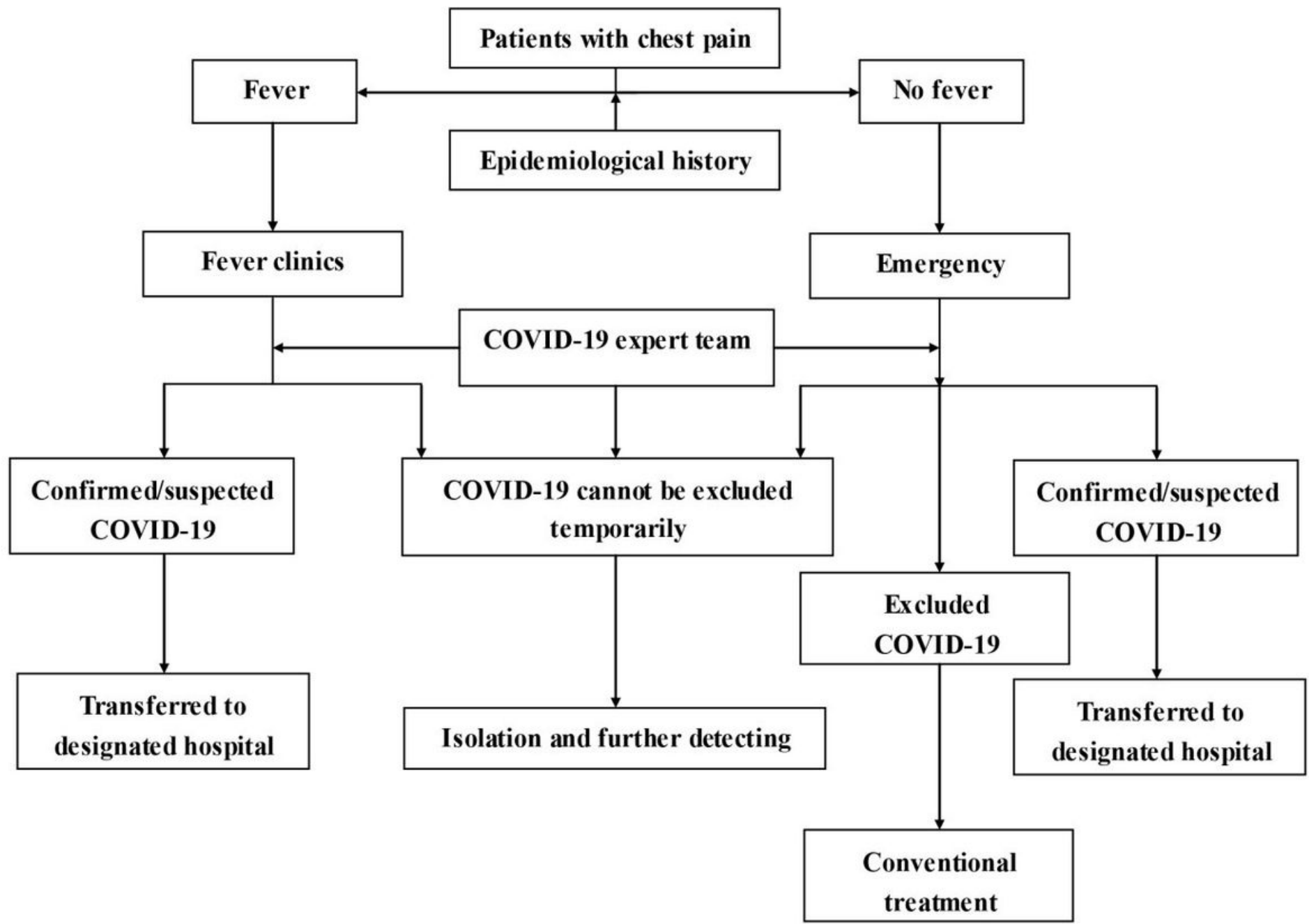

Figure 2

Flowchart of emergency procedure 

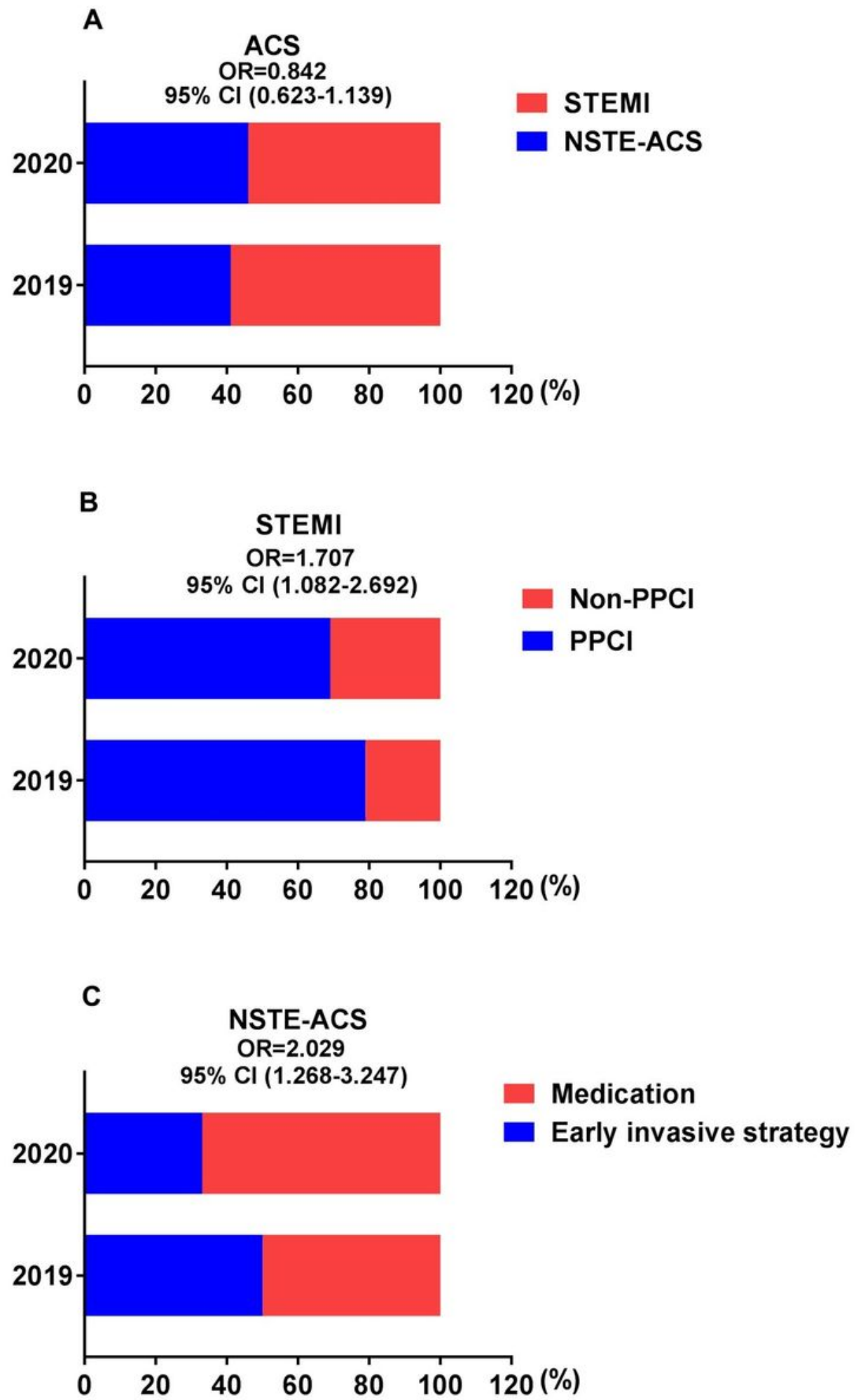

Figure 3

Constituent ratios of ACS and invasive therapy 